Binghamton University

The Open Repository @ Binghamton (The ORB)

The Society for Ancient Greek Philosophy Newsletter

3-22-1984

\title{
Ideals and Obligations in Plato's Ethics
}

Julius M.E. Moravcsik

Stanford University

Follow this and additional works at: https://orb.binghamton.edu/sagp

Part of the Ancient History, Greek and Roman through Late Antiquity Commons, Ancient Philosophy Commons, and the History of Philosophy Commons

\section{Recommended Citation}

Moravcsik, Julius M.E., "Ideals and Obligations in Plato's Ethics" (1984). The Society for Ancient Greek Philosophy Newsletter. 114.

https://orb.binghamton.edu/sagp/114

This Article is brought to you for free and open access by The Open Repository @ Binghamton (The ORB). It has been accepted for inclusion in The Society for Ancient Greek Philosophy Newsletter by an authorized administrator of The Open Repository @ Binghamton (The ORB). For more information, please contact ORB@binghamton.edu. 


\section{IDEALS AND OBLIGATIONS IN PLATO;S ETHICS*}

Thrasymachus' manifesto in the REPUBLIC is one of the most discussed texts in the history of ethics. Generations of philosophers have wondered if his amoral stance is really refuted by Plato's answer. In order to understand the answer we must first come to understand Thrasvmachus. Fven a cursory perusal should convince us that his position is more than a mere attempt at defining justice or rightnes ${ }^{1}$. The oft quoted slogan "justice is what is in the interest of the stronger" hides an analysic that can be bect labelled as moral scepticism. For Thrasymachus argues (338el-339a4) that all this talk about justice and its rational foundation is empty. What we call justice ic really a set of injunctions that those with power force upon us. This is not a definition, but rather a sceptical explanation of the data that philosophical definitions try to analyze. A modern statement of Thrasymachus' position would be: "what we all call justice is in fact nothing but whatever persons with power impose upon us." 2 If Thrasymachus is rieht, then there is no rational foundation for justice and rightness. Ethies should be replaced by a branch of political science that studies power and predictc or explains domination in different societies.

One would expect Plato to reply to Thrasymachus by showing that justice and morality can be given rational foundatione, and that invoking these notions is not just a sham perpetrated on us by the mightv. But this is not. what Plato does. Instead, he leads Tharsymachus to commit himself to further claims. In particular, he elicits from Thrasymachus a description of the life-ideal that he professes $(343 d-344 d I)$. This is the ideal of the tyrant, or the strong and powerful person.

This move should give us pause. For there ic no logical link between the two theses. Moral scepticism is compatible with anv number of life-ideals. I might agree, for example, that all this talk about what is right is merely a manifestation of what the rulging classes want, and then go on to proclaim as my life-ideal that of a quiet retiring individual with a few gentle pleasures and with no intention to dominate anybory.

Our key questions, then, should bo: a) Why does Plato link Thrasymachus' moral scepticism to a certain life-ideal? and b) how does he reply to these two theses?

Many modern discussions assume, that Plato's task is to challenge the claim that justice leads to misery and injustice lears to happines . In the course of wotking out thic scheme modern interpreters have to come to grips with the fect that Plato describes a certain inner psychological condition as justice, and thus needs to connect this notion of justice with the notion of justice as meeting one's obligations. Other interpreters try to show that, Plato defends the notion of just and fair dealings with others as intrinsically good, regardless of consequences for one's own happiness or that of others.

If Plato's reply is to show that justice pays rather than injustice, then he is an early example of a kind of utilitarianism. If he is showing the justice is intrinsically good, but in fact makes us also happv, then he is a Kantian with an additional - dubious - psychological thesis.

If one is to think that these are the only alternatives, then one is tacitly subscribing to a typical conception of ethicsh held in modern times according to which the main questions of ethics are those of utility an? obligation; and depending on how one links these two, one is a deontologist or a utilitarian. But not all ethical theories contain only these two components. For specifying utility must assume some answer to the question: "useful to whom, or to what kind of a person?" Thus a complete ethical theory must have three components. A) A substantive theorv of the Good (CTG from here on); i.e. a theory that specifies what it is to be human, and what it is to be a flourishing human. B) A theory of utility foe the 
individual and for $-2-$

individual and for collectives that specifies means to the substantive good, and ways of calculating the means. III. A theory of obligations both in terms of bonds between individuals, and in terms of societal links such as the distribution of goods, and the acceptance of rights.

A good example of a modern ethical theory that contains all three parts is that of John Rawls ${ }^{3}$. In the first two parts of his book Rawls develops the notion of justice as fairness, and in the third part he precents his STG. As Rawls " theory shows, a rational foundation for claims about juctice has to indicate what the justifications of these claims are, and how these are related to questions of utility and an adequate STG. An STG mav be a "thin" theory or one with much content. Even a hedonist has an STG, though a "thin" one. According to the STG of a hedonist, a flourishing human being is a creature that can and should have pleasures, and this capacity of his is of supreme importance. We shall see why Plato rejects this STG.

An STG may be related to matters of obligation in different ways. Typically, the connection will follow utilitarian or non-utilitarian lines. As we shall see, however, other alternatives are also open.

This paper has two main claims. First, it will argue that most of what is usually interpreted as Plato's ethics is concerned primarily with the establishing of an STG. Secondly, it will be shown that Plato's link between his STG and matters of obligation is a verv close one, and cannot be analyzed either along utilitarian or Kantian lines.

If one is to interpret Plato's ethics along the lines suggested, one arrives at the following outline of the REPUBIIC. The argument starta with two claims of Thrasymachus: i) moral scepticism and ii) the tyrannical sm. Plato's reply starts already in 353d3-354a9 (Bk.I.). He points out that since humans form a natural species, they must have certain natural functions and capacities ("erga"). The point of this passage is to shift the discussion from the question of what should be Thrasymachus' individual \&TG to what should be the STG of a human. Plato thinks that any rational person will accept this shift. Since we are humans, we should be interested in the substantive STG of a human. Plato may be oversimplifying things. Is there not a sense in which one could say: "So I am a member of the human species. So what? Why should I devote my life to developing those characteristics that would moke me an outstanding member of the species? Maybe I have more important aims? (While Plato may have such an "existential outcry", we should not underestimate the potential of an adequate response to such outcry.)

In Bk.IV. Plato gives the outline of his STG. This is his famous theory of the flourishing soul as inner harmony (436a8-444a2). Inner harmony for Plato includes a certain dominant role for reason. This role can be understood only if we see in the bsckground of REPUBLIC IV the philosophical psychology developed in the SYMPOSIUM. In 442 e4-443b5 Plato maintains also that a person with the right STG will adopt the attitude and conduct required by justice; $i . e$. the notion that encompasses our obligations and fairness towards others.

Books V-VII explain and justify the metaphysical and epistemological premisses involved in Plato's STG. In Books VIII and IX Plato compares his STG with alternatives and concludes not only that his STG is superior, but also that a person living according to this ideal will have his own enjoyments.

One argument for adopting this interpretation is that following the outline sketched here enables us to construct a much better detailed interpretation of the REPUBIIC than what we can achieve if we follow the assumptions adopted by those who try to force Plato into the utilitarian or deontologist moulds.

There is, however, one passage that has crucial direct bearing on our 
question. In 357cl-358a 3 Plato considers whether a notion like justice should be shown to be good for its consequences, or for its intrinsic merits, or on both counts. Those who think that Plato must have been a utilitarian or a deontologist, and that he is facing here this option, find it puzzling that Plato undertakes showing justice to be good on both counts. If he is a deontologist, he must be overplaving his hand, and if he is a utilitarian, then he must be inconsistent. But the difficulties with these modern interpretations go deeper than this quandary. For it is clear from the passage that Plato regards it as a real advantage if he can show justice to be good on both counta. This makes no sense if Plato was thinking either in the utilitarian or the Kantian frameworks. It makes, however, very good sense if we assume that Plato is considering here justice as a potential ingredient of his STG. For within an STG one wants to specify a basic or primary set of goods in terms of which the healthy and flourishing huaph is spelled out, and ong wants to show also what some of the cosequences of such an STG will be . Unless we wish to assume that Plato did not understand his own theory at all, we should start out at least initiallv with the hypothesis that the main parts of the REPUBLIC are devoted to spolling out the Platonic STG. He does not attack Thrasymachus moral scepticism iirectly. Instead, he presents his own STG, and shows Thrasymachus' candidate to be inadequate. He then goes on to show a close link between the adequate $5 \mathrm{~m} G$ and moral conduct.

At this point we should try to understand why Plato insists that Thrasymachus must have an STG. Plato seems to assume that anvone with a full set of principles for conduct will have, explicitly or otherwise, an STG. Though Plato gives no argument for this assumption, there are enough hints in the text to provide a basis for reconstructing the tacitly assumed argument. Plato sees that everyone addressing questions of right choice must, ascume some conception of the self as an acting agent, and that such a conception must be partly normative. The reasoning behind this thought is the following. One can try to explain human nature from an observer's point-of view. Onr would eventually arrive at a characterization that would form the basis for predictions about human behaviour. Plato, however, does not statt from this point of view. Plato, haven starts from the point of view of the acting agont asking: "what shall I do?" In order to give a rational answer to this question one must have a conception of the self with builtin priorities. A conception of the self without priorities would have to be a list of all of the parts, attributes, as well as trivial details of life history. Without priorities one might end up sacrificing one's emotional capacities for the sake of a toe, or one's ability to cooperate for the sake of a fleeting moment of pleasure. We must assume that some parts and attributes are more important than others. Up to a point biology helps us to set the priorities. It tells us that the heart ic more important than the finger-nails and the brain is more important than hair. But this loaves us with a lot of slack, and attempts to squeeze out priorities from allegedlv analytic delineations of what it is to be a human still leaves us without guidance for cases in which we must choose between feelings of attachment and the development of competitive excellences. Yet these are what William James would have called "forced options" for humans. An agent is a planning creature, and plans presuppose some overall scheme of priorities among human parts and attributes. The way Plato describes the acting and choosing agent suggests that thic is roughly the line of reasoning that he assumes as background. His STG as inner harmony with reason "in control" is at once a specification of a flourishing human and a characterization of the basic priorities that a rational planning agent should assume. For Plato all questions of utility are relative to this conception. Thracymachus too has an STG. He thinks that the primary goods are pleasure, and power. Plato challenges Thrasymachus' notion of power 
As we noted ahove, Plato does not give much of an explanation of how the STG is linked to public morality. He asserts that a human with the right STG will not commit acts of unfairness and injustice towards others. Hence one should consider a few ways of filling out the argument.

Al. This supplementary argument could be captured by the slogan: "inner harmony leads to harmony with others." Thus construen Plato advances here a psychological thesis. It would asert that a person whose inner harmony allows reason to specify ends, whose desires and attitudes are lead by reason ( $i . e$. the objects of the desires will have characteristics that warrant the desires or attitudes in question) and whose reason spells out both the constituents and appropriate means for a flourishing life, willnot, have desires or attitudes determining his actions that would lead to immorality.

A2. Plato might have thought that a person with the right STG, i.e. the inner harmony spelied out above, would find public morality to be useful. A3. The tacit Platonic argument could be that persons with the right STG require (or necessarily constitute) a kind of community for which moral conduct is essential.

of these alternatives $\mathrm{A} 2$ is the weakest candidate. For though acting with fairness to others would be much preferable from the point of view of maintaining the sTe than acting immorally, the moral conduct mioht have such sources as benevolence or sympathv, and under certain circumstances these sources take attention away from the pursuit of reason and understanding. The most that one could say is that acting with unfairness towards others would turn the soul away from the pursuit of the right GTG. Thus A2 gives us a negative reason; $i$.e. one that says why a human is boing harmed by immorality. A2 does not give us grounds for pursuing the positive things that go into being a human who ic fair and meets obligations.

This negativety carries over also to some extent to Al. It is easy to chow that under normal circumstances a person with the Platonic sTG would not have interest in acts like murder and adultery. It is much less easy to show that such a person might never resort to such activities, even if in some contexts these could be shown to be the least disastrous mmans to securing the pursuit of understanding. Also, Al does not say anything about the kinds of conflicts in which increasing my knowledge and rationality clashes with the development of rationality in others. Al could be invoked to show that the Platonically good person would not be possessive. This is, however, not the same as showing that such a person would have basic respect for others.

It seems, then, that from the point of view of a Platonistic philosoph A3 would be the most appropriate candidate for filling out the argument, linking the STG with public morality. Plato believes that the development of rationality and understanding is a necessarily cooperative enterprise. For Plato self knowledge involves understanding the rationality that is within a person, and this - in his view - requires a community. Furthermore valuing rationality leads - according to Plato - to a desire to maximize its instantiations. This again requires a community. Thus the establishing and maintaining of inner harmony requires a community. This community is based on shared ideass and cooperative enterprises. Members of this community would see each other as partners and contributors in the project of increasing knowledge and rational control in humans. Regarding each other in this manner would constitute the basis for mutual respect and taking interest in the welfare of all members of the community. Without such respect and interest one would cut oneself off from sources of self knowledge and from the context within which the pursuid values can be maximized. 
We know from Thrasymachus' case that Plato's response to persons with the wrong STG is education. But Plato is silent on what to do if education does. not help, and persons like Thrasymachus threaten the Platonic community. Nor does Plato say much about distributions of goods and the assignments of rights. One can see, however, that in a Platonic community theso would not be issues of paramount importance.

As we saw, Al is a psychological thesia while A3 is a conceptual claim. While A3 seems to be the best candidate for closing the gap in the argument, $\dot{\mathbf{x}} \mathbf{x} \mathbf{x} \mathbf{x}$ there is a real possibility that Plato did not iistinguish sharply between $\mathrm{Al}$ and $\mathrm{A} 3$.

Regardless of whether he opted for Al or A3, within Plato's framework the simple question: "does justice pay?" makes no sense. Only when provided with proper qualifications does the question become worthy of reply. There are at least five qualified versions of the question that merit some consideration.

Vl. "Does justice, in the sense of acting morally towards others, pay?" This question arises only if Plato were to construe the link between his STG and morality along the lines of A2. We saw already that this is an implau. sible interpretation.

V2. "chould justice in the sense of acting morally be a part of an adequate STG?"

We saw that Plato spells out his STG in terms of what we are and should be, and not in terms of what we do. Thus it is unlikely that plato would have considered this question. He would have been more interested in showing that acting morally is a consequence of his STG.

V3. "does inner harmony - as part of the adequate STG - pay?"

This question is senseless for Plato, because one cannot ask whether an STG or one of its parts "pays". For the STG is a partial specification of the agent in the context of the question: "is $x$ useful to a human?" If one construed inner harmony as one of those things that can be juiger useful or harmful, then one would have to ask once more: "useful to whom?" or "useful to what kind of person?" and this question would demand further specification of the flourishing human agent. This regress has to stop somewhere. For Plato it stops with inner harmony as his STG, for Rawle it stops with his theorv of the good that includes rationality and self respect. If one construed V3 as asking whether inner harmony brought pleasure, then one would be tacitlv embracing a non-Platonic STG, namely one which specifies the gaining of pleasure as the key ingredient in an STG.

V4. "Should justice in the sense of inner harmony be a part of an adequate STG?"

Since the answer to this question is Plato's defense of his STG and his comparisons with alternative STG' $^{\prime}$, the answer would be neither utilitarian nor Kantian. When Rawls savs that "humans should be rational" or Plato says that "humans should have inner harmony", they are using "should" in a sense that is neither utilitarian nor a 'should' of obligation. This 'should' indicates not utility or obligation, but the 'should' in terms of which one spells out what it $i$ to be a well functioning human agent relative to whom questions of utility can be raised and relative to whom obligations are specified.

V5. "Is the life of a person with inner harmonv more enjoyable than the lives of persons with different STG's?"

This question assumes that one can compare different tvpes of pleasures across the board. Thus one way of diffusing V5 would involve showing that the Platonically good person enjoys life but that these enjovments differ qualitatively from enjoyments to be had while following other STG's, and that in fact different STG's are likely to involve pleasures that do not allow mere quantitative comparison. Another way to deal with V5 would 
$-6-$

take some sense of 'pleasure' that people on a pre-analytical common sense level can agree on, and then show that in this sense of 'pleasure' the Platonically good person ejoys life more than persons with alternativo cTG's. This would have to be argued as an independent psychological thecis; it is not required by nor does it follow from the adequate specification of an STG.

Thus we see that of the various versions only. V4 and V5 make sense for Plato. In showing different ways of dealing with V5 we have gone bevond the texts. Indeed, one might argue that the failure to distinguish clearly between the different possible responses to V5 underlies some of the conptual obscurities of the argumenta tkx towards the end of Book IX. In any case, we see that the only versions of the "justice pays" principle that make sense for Plato leave him as not committed to hedonsm or to consequentialism in general.

So far we have discussed Plato's STG without having examined in detail its content. One of its key features is the condition that reason must "rule" over the soul. Unpacking this metaphor will yop consiterable insight

We can say initially that according to Plato the control of reason involves our emotions, feelings, attitudes, and desires having their propor objects. This requirement needs justification. Why should we not say that any desire or emition should be satisfied or fulfilled as long as such proceses will bring pleasure? Plato's reply has two parts. In his examination. of pleacure in the GORGIAS and the PHILEBUS he posite

Pl. The plasticity of human nature. A human can experience enjoyment in connection with a wide variety of activities, and can change his inner state so as to alter the sources for his enjoyment.

Thus for example if a person enjoys eating a lot and subsequently convinces himself that this is bad for him, he can not only change his oating habite but can also become a person who enjoys eating less and only helthy food. Again, if a person enjoys dominating others and convinces himsolf that i.t would be better to lead a life of cooperation and sharing, then such a person is able to change his desires and emotions so that he will enjov the sharing and the cooperation.

This shows that Plato has a dynamic view of human enjoyment. According to the static conception humans have a basic set of pleacures and enjovments that correspond to fixed needs, and our task is simply to seek the best means for the meeting of these needs. The dynamic conception sees most human nooris as dependent on our conceptions of ourselves. Changos in outlook and personality can change neers and hence sources of enjoyment.

PI. states a paychological fact. It does not lead, by itself, to a normative critique of pocsible objects for desires or emotions. In order to lay the foundation of such a critique, we need the conjunction of $P I$ and another principle:

P2. Not all object of desire or attitude are of equal worth.

For Plato a rational life involves enjoying those things that one values as well. Pl. tells us that we can change our sources of enjovment, and P2 tells us that such changes can be undertaken from the point of view of proper evaluations.

Plato's theory of rational desires is assumed in the middle books of the RFPUBLIC. The details are laid out in SYMPOSIUM 210-212, the famous passage of the ascent to Beauty.

A key condition for the understanding of this text is the realization that Plato uses 'eros' to denote a generic relation which includes what we would call desire, attitude, love, aspiration, and interest. Plato draws these distinctions solety in terms of the differentiations of objects for eros. 
$-7-$

- In modern philosophy we differentiate different desires, attritudes, and emfions either in terms of causal mechanisms that bring these about, or in terms of introspectively registered qualities. Plato rejecta introspection as a reliable guide for mental topography, and he does not know of causal mechanisms of the required sort; hence his reliance on objectual differontiations. His theory has advantages when applied to certain mental states. His is a "magnet-theory" of eros, for he sees objects of various states or dispositions as magnets that can evoke various attitures. The purely objectual specifications require us to translate one Greek word, 'eros' with a variety of English expressions such as desire, love, liking, attiture, emotion, aspiration or interest. The divantage of plato's theory is that he can explain shifts between these non-rational states as the agent moves his attention from one object to the other. The framework is also advantageous when it comes to accounting for intellectual interest. Platonic "eros" for mathematics is being interested in mathematics. We know of no causal mochanis that will explain the rise of intellectual interest, and introspectively re-gistered qualities do not enable us to demarcate the various intellectual interests of a person. Finally, Plato can point to a common element that even within the modern framework all types of "eroc" share. For each of these involve valuing (or "holding dear" "philein") an object.

Plato sets up a general framework for rational "eros" and then within this he has more specific proposals. A rational "eros" in the general sense of this notion has the following structure:

person $P$ has eros $E$ towards an object $x$ in virtue of $x^{\prime} s$ characteristic $C^{\prime}, C^{\prime \prime}, \ldots$...

where the attribute-set is a sibset of the total attributos of $x$. (In order to simplify exposition, we shall make the obviously unrealistic assumption that the eros is in virtue of one attribute $\mathrm{Cn}$ ). The "in virtue of" link is to show that though $\mathrm{Cn}$ may play a causal role in the development of $E$, its primary role is that of justification. So thic type of eros is to be contrasted with those in which Cn might play a causal role in the development of $E$, it would not be invoked by the agent as justification.

Plato's special thesis within this general framework is that only certair attributes can function as adequate justifications. For example, one can admire another person for the right or for the wrong reasons. The same can be said for desires, interest, etc. Thus reason rules the soul when eros develops in a rational manner - as specified above - and the eros-grounding attributes are the appropriate ones. Discovering new attributes in an objcet opens up the possibility of new evaluations, and hence new "eros". This is, then, the first part of Plato's theory. The second part involves progression through four stages. This too is an integral part of the notion of inner harmony. We start with

$S i$. $P$ has $E$ towards $x$ in virtue of $C n$.

It is clear both from the SYMPOSIUM and the REPUBLIC that Plato is considering this case under idealized circumstances. We must assume, forf xample, that the eros developed solely in virtue of the recognition and valuation of $\mathrm{Cn}$, and that $\mathrm{x}$ has no attributes that would cancel out $\mathrm{Cn}$ 's magnetism. Furthermore, if $\mathrm{Cn}$ is the right kind of attribute then it must lead to or be a constituent of what Plato regards as goodness. Finally, the history of our relationship with $\mathrm{x}$ is ignored, and so are possibilities of reciprocitv, limitations on information, attention span, and the limits of our energies.

Understood this way SI leads to $x^{\prime}$ s particularity dropping out of the picture. The only relevant condition for $E$ is that the object has $C n$. Hence Plato assumes that the rational person will move from $S I$ to

S2. $P$ has $E$ towards all and any $x$ that has $\mathrm{Cn}$.

For once we focus on the attribute that makes $x$ a suitable object for $E$, we can generalize and see that under the appropriate idealization , any+hing possessing the right attribute will serve as the object of $\mathrm{E}$. 
$-8-$

By abstracting away not only from the uniqueness of any one $x$ that has $\mathrm{Cn}$, but also from the fact thst $\mathrm{Cn}$ happens to have instances, Plato expects the good human to arrive at:

S3. $P$ has $E$ toward $C$.

This grates on the modern ear. One can admire all persons of courage, but how can we admire courage itself? Our difficulties, however, mav stem from an overly restricted interpretation of eros. 3 is more plausible if we take it to be basically valuation or interest. If $I$ value courageous persons, then I value courage. If I take an interest in all beautiful things, then, given the idealization conditions mentioned above, I will take an interest in beauty. There are three reasons why Plato wanto to go beyond 52 and move to 53 . One of these is the metaphvsics within which the theory is couched. The other is that this enables Plato to deal with the fact that Forms are only contingently instantiated. If my interest ix would be rostricted to beautiful things, then I would have no interest in beauty when it is not instantiated. Thirdiv, it is $S 3$ rather than 22 that leads to:

S4. If $P$ has $E$ towards $C n$, then $P$ wants $C n$ to have as many instances as possible (or: $P$ wants "as much Cn as possible").

This step captures the steps of creation that are parts of the ascent of the SYMPOSIUM, and gives for these motivation. We move from 53 to 54 , because if we have a real interest in $\mathrm{Cn}$ and value it highly, then - ceteris paribus - we will want "aspmuch of it as possible"; i.e. have it instantiater as hny times as possible.? If one values courage, then one wants as many instances of it as possible. Furthermore, our interest at this stage is in having $c n$ instantiated at any time and in any place, The interest i- not restricted to wanting instances for ourselves.

The eros developed at this stage $i s$ neither egoistic nor altruistic. In the early stage we have an egoistic eros; we want something for ourselves. But as we concentrate on the reason that leads us from one eros to the other, we leave egoism behind. Our eros comes to have first a more generalizer and then a more abstract object, and it makes no sense to want an attribute all to oneself. If we have a genuine interest in an attribute, then we would not want to be its sole instance.

The process is cumulative. As we move along, we do not abandon tho previous objects of eroc. If I desire healthy food, then eventually the Platonic theory of how reason should control my atti.tudes will lead me to wanting healthy food in the world in general. This does not mean that I ton't want healthy food formvself.

The attribute ch is in some cases, as the example of healthy food shows, a species of a larger genus. There are species af beauty, health, knowledge, etc. In the development of understanding, these relationships will be discovered. This should lead to the appropriate morifications of eros. Thus there is a general condition of E-development:

S5. If $\mathrm{P}$ has $\mathrm{E}$ towards $\mathrm{Cn}$, and $\mathrm{Cn}$ is a "part" of kind of a more generic Form $C$, then $P$ will have $E$ also towards $C$.

Thus, for example, we move from eros towarda a certain kind of beauty to eros for beauty itself.

Let us take again the example of healthy food. Starting with a desire for healthy food. I come to form a certain attitude towards all healthy things, and eventually towards health itself. I will then want to seo as much health in the world as possible. Of course, one needs to add that my desires need to be compatible with each other, and that other considerations might constrain my efforts to have more health in the world.

I might also develop a yearning for having sxiend. This should lead me to wanting anyone with those attributes as a friend, and eventually I should be led to the point of seeing the value of friendship, and hanghewatigg to posskblowards there being as many friends and friendship 
$-9-$

Alternatively, one might become interested in a mathematical proof because of its abstractness, explanatory power, and elegance. One would then generaliz the object of interest to anything with those attributos, and after ono has focussed on the attributes themselves, one would want to create as manv instances of elegant mathematical proofs as possible. Similar considerations will bear on examples involving admiration or approval.

As we can see. Platonic eros is not the eros of a consumer. Orinarily we think of a person who desires food as someone who wants food for himsolf and once he has it he consumes it. But the Platonic person, though ho will not starve, will go further than that. Having enjoyed the food, he will focus on its good making characteristics, and after the generalization of the object of eros he will take an interest in the goodnes of the product and will want to have as much of it available to mankind as possible. In the case of the objecta of noetic interest the matter of consumer-attitude does not arico, since these objects cannot be consumed in any clear sense. More than one person can work on the same mathematical proof, but only one person can consum a given portion of food.

The Platonic analysis of eros works best for attitudes like interest, admiration, or approval. Plato probably did think that all of the different types of eros should culminate in intellectual interest, or at least that, intellectual interest should be the highest form of eros, even if we do keop all of the other types.

We can see how egocentricity is dissolved even in the case of tho other types of eros. If I want money because it makes mo happv, then I will - on reflexion - want everything that makes me happy. But if happiness is something objectivelv valuable, then I should be interected in it, and thus in its cpeeading as far as possible, regardless of whether it is mv happines or that of others that is being promoted.

This analvsis of the Platonic attitudes helps us to understan what it is for reason to "rule". The Platonic STG ascigns to reason the following rules a) reason fixes ultimate ende since it shows us what has objective value $\mathrm{b}$ ) reason informes our attitudes in the manner specified above $c$ ) by informing our attitudes it enables these to counteract impulses and appetites d) it elicits intellectual interest from the healthy person.

At least three factors should be mentioned that Plato invokes in justifvi this CTG. First, as we saw already, Plato thinks that inner harmony fulfilla our human functioning, or "ergon". Secondly, as his description of education in hi- Cave-analogy shows, inner harmony realizes freedom, for a person with inner harmony is free to realize ends that he chooses on reflexion, and ic free to change in directions deemed valuable. Thirdly, such a person achieves selfsufficiency (IYSIS 215a) since he i- not depentent for his welfare on accidental environmental features, or on the opinions of others.

Our analysis of Plato's STG showed that from the point of view of oros the objects are always analyzed as merely coinstantiations of attributec 9 . It is important to note, however, that from the point of view of eras the self too is analyzed this way. Plato does not give different analvaos for respect for others and self respect, or admiration of others and admiration of the self. If I approve of myself or respect mvself, or love myself, this must be - if warranted - in virtue of my possessing a restricter set of attributes. This means, however, that the same steps applv as in the case of other objects. Thus the adoption of the Platonic attitudes lears to a conception of the self according to which the self is transformed into a moro set of coinstantiations ist as much as other objecta are. This should change our ways of interpreting "wanting something for myself". For once the Platonic attitudes are adopted, this will amount to saying that I want instantiations of certain Forma in such a way that these should be causally related to a feftain special "bundle of qualities" namely myself. But once it is put that , we see why Plato would regard such a restriction as arbitrary. If the attributes in question do have objective worth, why should their instantiations 
be related to a set of coinstantiations to which they happen to have a causal link? If the attitude is warranted, then I should want to have the object have as many instantiations as possible, regardless of their contingent causal relations. Self-interest becomes in this way transformed into interest in the Good and its parts and instances. This is the deepest aspect of Plato's "reason rules" principle.

Evidence for this interpretation is provided not only by the fact that we can read the relevant passages in the SYMPOSIUM and the REPUBLIC in a moro satisfactory way, but also directly by REPUBLIC 547b7-c4, where Plato makes i+ clear that the emergence of interest in the self and the accompanving possossi veness is caused by the abadonment of reason. This is, once more sthengt to the modern ear. We tend to associate reason and seif interest, and not to oppose them. But the see that by "rationality" Plato means the conceptions of self and other objects that was sketched above, then this passage makes good sense. Once I stop seeing myself and other objects of eros as "bundles of qualities". I $t$ see them as the unreflective person would; the self is a center of individuality, and other objects become important because of their alleged uniqueness that they have for me in view of my interactions with them. Once we see these implications of the platonic psychology, we can solve two aroblems set by the interesting analvsis of eros provider by G. Santas ${ }^{10}$. Ome of these concerns the thesi that eroc indicates ieficiencv. Now it is true that initially the person who develops eros towaria something feels a deficiency in himself. But by the time his attitudes are transformed in the manner outlines above, the deficiency too is generalized, and is construed as the world lacking sufficient numbers of instances of the object of eras. Again, there might be - on the surface - a conflict between eros towards obtaining something, and the eros of keeping what we wanted. But the truly Platonic eros dissolves this distinction. "Obtaining" starts the process, but by the time we moved through sl - 54 , what we want ic more instances of the object; and this amounts to both obtaining more of the $\mathbb{P}$ iorm in this world and maindining it.

In conclusion one should note the incomplete charactor of the ethics that falls out of Plato's $\triangle T G$ and the close link he envisages between this anc matters of obligation. We are not told how to resolve confilicts between different goods, or between different realizations of the same good. We are not told anything about how to dictribute goods, and we are not given anv grou for rights. It is not clear how Plato would handle rational wishes for something that we want instantiated only in rare cases. For example, one might want a certain type of doctor or teacher to exist without wanting it to be the case that every doctor or teacher should be like that. One would have to go much beyond the Platonic texts to construct an ethics that deals with all of these issues. Even if such a reconstruction were to be made, we might find that mush of ethics would be autonomous in the sense that it would have no close link to Plato's STG.

There are a few arguments towards the end of Book IX about the STg Iearin to a pleasant life. We have seen already that this can be taken in at least two 4 se. If Plato were to argue that there is a general notion of pleasuro, in terms of which the Platonic human has more of this than humans with other STG'S, then this would have to be a separate argument, independent of the justification of the STG. The construction of the REPUBLICi $i=$ like the dialectical construction of other dialogues such as the MENO, PHAFDO, SYMPOSIU and SOPHIST. The dome-like structure indicates that the deepest theories form the inner core of the dialogue, and that what is in the beginning and the end are on a more concrete and common sensical level. Hence one should not, attribute too much importance to these - clearly inadequato - argument.s about pleasure at the end 11 . 
$-11-$

We should note now that Plato is not only proposing a new way of doing ethics but is also adgressing a major question in classical Greek thought. As Irwin pointed out ${ }^{12}$ the Greeks before Plato were already interested in the question of how to relate one's own interest with the public good. Plato's answer is neither a Kantian nor a utilitarian one. His answer is that this way of phrasing a question about ourselves and others presupposes a falso conception of the self and of the human STG. When we come to understant ourselves adequately and develop the adequate $S T G$, the original question

dissolves into a demand for efforts towards instantiating the Good, whenever and wherever possible.

Stanford University

Julius M. Moravcsik

\section{NOTES}

* Many of the ideas contained in this paper originated in mv "On What We Aim at. and How We Iive" in The Greeks and the Good Life ed. D. Depew, , Hackett, Indianapolis $1980 \mathrm{pp} .198-235$. I am indebted for very helpful criticism of that paper by T. Irwin and Kurt Baier; the final version received further helpful comments from Michael Bratman.

1. The multiple significance of Tharsymachus' claim has been recognized by Julia Annas, though she gives a different interpretation from what is proposed below. Cee Julia Annas An Introduction to Plato's REPUBLIC Oxford Univorsity Presa 1981 pp. 36-37

2. One can compare this to the emotive theory of ethice. Such a theorv does not attempt to give a symonym for 'good', but rather explains its use by claiming that its primary function is to express some emotion or attitude.

3. John Rawls A Theory of Justice Harvard University Press, 1971.

4. The difficulties of interpreting Plato as either a utilitarian or a Kantian cen be seen from the work by J.D. Mabbott "Is Plato's REPUBLIC Utilitarian? Originally in Mind 1937, reprinted in Modern Studies in Philosophv; Plato vol. II. Doubleday, New York, 1971 pp. $\overline{57-65 .}$

5. This is also Rawls strategy. He explicates the notion of primary or basic good, and then shows that this is compatible with fairness, leads to stabil in society, etc.

6. Though much of this material derives from my earlier work on the SYMPOCIUM, this particular point has escaped me in my earlier work. See J. Moravcsik "Reason and Eros in the Ascent-Passage of the SYMPOCIUM" in Essays in Ancient Greek Philosophy ed. John Anton and corge Kustas Albany N.Y. $1971 \mathrm{pp} .285-302$

7. The claim seems more natural if we assume a mass-term interpretation of moral Forms at this stage; or at least a failure to iistinguish the mass from the count term interpretation. I am indebter at this point to iiscussi: with Nicholas Denyer.

8. On this view the Good is not at the top of a hierarchy of all objecta of' satisfaction. Rather, it is a magnet that gives the proper orientation and hence meaning for human lives. For a different view see $T$. Irwin Plato's Moral Theory Oxford University Press, Oxford, $1977 \mathrm{pp}$. 51-52 and p.224.

9. This point was made in my earlier work on the SYMPOSIUM (see above) and in some of the writings of Gregory Vlastos. But it is important to see that this is a claim about how we see objects within the erotic attitude. It is not a metaphysical claim; in order to assess Plato's ontology of the individual, one would have to bring in passages from the TIMAEUS.

10. Gerasimos Santas "Plato on Love, Beauty and the Good" in Nepew ed. Op.cit. pp. 33-68.

11.For a more sympathetic treatment of these arguments seo Julia Annas op, cit. pp. 307-309.

12. T. Irwin op.cit. pp. 16-17. 